\title{
Percutaneous transluminal dilatation of transplant renal artery stenosis
}

\author{
R. N. RANKIN* \\ M.D., F.R.C.P.(C.) \\ R. A. Ulan** \\ M.D., F.R.C.P.(C.)
}

P. A. KeOWN**

M.D., F.R.C.P.(C.)

C. R. StilleR**

M.D., F.R.C.P.(C.)

$*$ Department of Radiology, and ${ }^{*}$ Department of Medicine, Nephrology and Transplantation, University
Hospital, London, Ontario, Canada

\begin{abstract}
Summary
Percutaneous transluminal angioplasty has been applied to the treatment of transplant renal artery stenosis in 3 patients, 2 with severe hypertension resistant to medical therapy, and one with graft dysfunction related to the presence of the stenosis in the early post-transplant period. The clinical courses of the patients before and after angioplasty are illustrated and the usefulness of the technique in this difficult situation stressed.
\end{abstract}

\section{Introduction}

Persistent hypertension in the renal transplant recipient is a frequent clinical finding accompanied by considerable morbidity and mortality; the intensive search for a potentially curable cause is thus of prime importance. Stenosis of the transplant artery, reported to occur in $5-12 \%$ of cases (Kaufmann et al., 1977; Ricotta et al., 1978) is associated with the development of severe and resistant hypertension, and the progressive reduction in renal blood flow may ultimately jeopardize graft survival (Schramek et al., 1975). Surgical correction, initially the therapy of choice, is accompanied by an obvious risk in the immunosuppressed patient and is frequently technically difficult or impossible in this situation. Chemotherapy is similarly often unsatisfactory, limited by patient compliance, adverse side effects and an appreciable failure rate. Furthermore, medical therapy is ineffective in increasing renal blood flow to the graft, and satisfactory reduction in the blood pressure by this means may result in a rapid deterioration in renal function.

The technique of transluminal angioplasty has had good short-term success in the relief of stenoses in native renal arteries (Grüntzig et al., 1978; Katzen

Reprint requests to: R. N. Rankin, M.D., Department of Radiology, University Hospital, London, Ontario N6A 5A5, Canada.

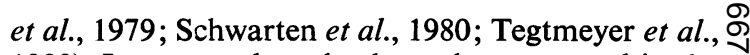
1980). Its success has also been demonstrated in the $\dot{\omega}$ transplant kidney where stenosis is implicated in 8 hypertension (Diamond et al., 1979; Mathias, Rau 음 and Kaufmann, 1979; Sniderman et al., 1980).

The utility of the technique in this difficult 3 situation is further illustrated in the description of 2 patients; and its possible use in preserving renal $\vec{\oplus}$ function is illustrated in the account of a transplagt $\stackrel{\infty}{-}$ in a third patient.

\section{Case reports}

Patient D.H.

A 24-year-old woman developed chronic renal failure due to reflux nephropathy. Haemodialysis $\varrho$ had been instituted in 1975 and bilateral nephrec- $\overrightarrow{0}$ tomy performed in preparation for transplantation. 3 The blood pressure was consistently normal $(130 / 80$ ? $\mathrm{mmHg}$ ) during the period on dialysis, and cardiomegaly was clinically and electrographically absent. 학 Uncomplicated cadaveric renal transplantation was $\underset{-}{-}$. performed in July 1979 and conventional immuno- $\frac{0}{3}$ suppressive therapy commenced with prednisone $(100 \mathrm{mg} / \mathrm{day}$, decreasing to $50-30 \mathrm{mg} / \mathrm{day}$ at one 윽 month) and azathioprine ( $2 \mathrm{mg} / \mathrm{kg} /$ day). Allograft function was excellent and 2 mild episodes of acute $\triangle$ rejection responded satisfactorily to i.v. methyl- $\frac{7}{0}$ prednisolone. The patient was discharged in Sept-

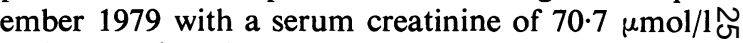
and a BP of $130 / 90 \mathrm{mmHg}$.

Severe hypertension, resistant to medical therapy, developed rapidly and progressively over the ensuing $\omega$ 8 weeks despite a progressive reduction in maintenance prednisone therapy $(17.5 \mathrm{mg} /$ day $)$. She was re-admitted for evaluation in October 1979 at which time her BP was in the range of $170 / 120 \mathrm{mmHg}$. Left ventricular hypertrophy with strain was noted on $\frac{0}{0}$ ECG, having developed since transplantation. $\overrightarrow{\mathbb{D}}$

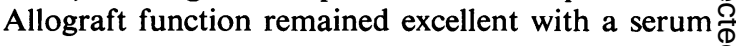


creatinine of $79.6 \mu \mathrm{mol} / 1$ and a creatinine clearance of $1.5 \mathrm{ml} / \mathrm{s}$. A bruit was audible over the transplanted kidney. Peripheral plasma renin activity was markedly elevated at $56 \cdot 1 \mu \mathrm{g} / \mathrm{l} / \mathrm{hr}$ (normal: $0.5-1.5$ $\mu \mathrm{g} / \mathrm{l} / \mathrm{hr}$; supine, $100-180 \mathrm{mmol} \mathrm{Na} / 24 \mathrm{hr}$ ). Transplant angiography demonstrated an elongated tight $(60 \%)$ stenosis of the donor renal artery originating at the arterial anastomosis and extending distally for approximately one $\mathrm{cm}$. Intrarenal vasculature was normal with no evidence of rejection or other pathology. Extension of the stenotic segment into the hilum of the kidney rendered surgical correction technically impossible. Percutaneous transluminal angioplasty was performed in November 1979 and was well tolerated. Within $6 \mathrm{hr}$ following the procedure the diastolic pressure had fallen to $85 \mathrm{mmHg}$ and all antihypertensive medications were withdrawn. The patient was discharged asymptomatic on the fifth post-intervention day. Her BP has remained under excellent control at $130 / 90 \mathrm{mmHg}$ on hydrochlorothiazide $50 \mathrm{mg} /$ day with an 8 -month followup.

\section{Patient O.N.}

A 20-year-old man developed chronic renal insufficiency on the basis of reflux nephropathy. Haemodialysis had been instituted in 1977 and bilateral nephrectomy performed in preparation for transplantation. Blood pressure remained normal $(130 / 80 \mathrm{mmHg})$ without medication during the period of dialysis. Uncomplicated cadaveric renal transplantation was performed in March 1979. Conventional immunosuppressive therapy (see patient D.H.) with prednisone and azathioprine was instituted. Excellent allograft function was achieved and the serum creatinine fell to $88.4 \mu \mathrm{mol} / \mathrm{l}$. One mild episode of acute allograft rejection was successfully treated with i.v. methylprednisolone.

Three weeks after transplantation, severe and progressive hypertension developed. Maximal doses of propranolol, hydrallazine, methyldopa and spironolactone were added sequentially but satisfactory control was not achieved. The patient was admitted for evaluation in September 1979 at which time his BP was $160 / 110 \mathrm{mmHg}$ despite intensive medical therapy. No retinopathy was observed but chest $\mathrm{X}$-ray and ECG revealed cardiac enlargement and early left ventricular hypertrophy. Allograft function had deteriorated slightly and serum creatinine was $123.8 \mu \mathrm{mol} / \mathrm{l}$ and creatinine clearance $64 \mathrm{ml} / \mathrm{min}$. A bruit was audible over the transplanted kidney. Plasma renin activity was markedly elevated at $26.8 \mu \mathrm{g} / \mathrm{l} / \mathrm{hr}$ (normal: $0.5-1.5 \mu \mathrm{g} / \mathrm{l} / \mathrm{hr}$; supine, $100-180$ $\mathrm{mmol} \mathrm{Na} / 24 \mathrm{hr}$ ). Renal angiography demonstrated a high-grade $(>50 \%)$ stenosis at the arterial anastomosis site. Intrarenal vasculature was normal with no angiographic evidence of rejection or other pathology. Surgical exploration of the anastomosis was performed but correction was technically impossible owing to the extreme proximity of the stenosed segment to the hilum of the kidney. Following satisfactory wound healing, the patient was discharged on continuing medical therapy.

Over the subsequent 6 weeks the BP remained resistant to medical control and clinical deterioration occurred. The patient developed occipital headaches, increasing in frequency and duration, necessitating re-admission. Percutaneous transluminal angioplasty was performed in November 1979 at which time his BP was $170 / 116 \mathrm{mmHg}$. The procedure was uncomplicated: over the ensuing $24 \mathrm{hr}$ the BP fell to $130 / 80 \mathrm{mmHg}$ and all antihypertensive medications were progressively withdrawn. The patient was discharged asymptomatic on the fourth post-intervention day and the BP was under excellent control in the range of $130 / 90 \mathrm{mmHg}$ on only minimal therapy (spironolactone, $25 \mathrm{mg} 4$ times/day; hydrallazine, $25 \mathrm{mg}$ thrice/day) for nearly 3 months. After this time he underwent severe and progressive rejection necessitating eventual transplant nephrectomy.

\section{Patient R.B.}

A 32-year-old man received a cadaveric transplant in April 1980. No significant problems were encountered at operation, though no urine output from the graft was noted.

The patient was placed on cyclosporin A immunosuppression and was immunologically negative with no further therapy throughout. An initial rise in urine output postoperatively over his pre-transplant level of approximately $600 \mathrm{ml} /$ day was noted in the first week (Table 2) with a continuing rise in serum creatinine necessitating haemodialysis. By the second week post-transplant urine output had fallen to pretransplant levels, nuclear medicine studies during this period showed an unchanging picture of poor renal function with a steady rise in renographic activity up to $30 \mathrm{~min}$, with no peak reached, and a nephrographic aortic bifurcation to kidney transit time of between 3 and $6 \mathrm{sec}$. This was felt to be in keeping with acute tubular necrosis. The opposite kidney from the same donor was known to be functioning well, at this time, in a different recipient.

Transplant angiography was performed on day 16 , and showed no significant intra-renal abnormality. There was, however, a tight stenosis at the arterial anastomosis with some irregularity of the proximal one $\mathrm{cm}$ of the transplant artery. Pressure recordings across the stenosis done with a one-mm outside diameter catheter gave a mean BP of $115 \mathrm{mmHg}$ proximally and $55 \mathrm{mmHg}$ distally. The patient was not hypertensive and renal vein renin sampling 
showed normal values from all sites sampled, including native and transplant renal veins.

Angioplasty of the stenosis was performed on day 19 after transplant without complication. The last haemodialysis was on day 20 , and urine output steadily increased from this time with a progressive fall in serum creatinine to $265.2 \mu \mathrm{mol} / 1$ at the time of discharge. Pressure recordings were not repeated after angioplasty because of procedure time. Nuclear medicine scans improved steadily with a renogram peak time of 3.5 min being achieved at the time of discharge, and a nephrogram aortic bifurcation to transplant time of one sec.

The patient has continued to do well for 3 months after angioplasty with continued good urine output and serum creatinine levels in the range of 221 to $265 \cdot 2 \mu \mathrm{mol} / \mathrm{l}$.

\section{Discussion}

Although the aetiology of transplant artery stenosis remains largely speculative a number of factors may be implicated: fibrosis or scarring at the anastomotic site may produce a localized arterial narrowing (O.N.) while preservation trauma and immunological factors have been implicated in the development of elongated post-anastomotic stenoses (D.H.). That stenosis of the transplant artery was the cause of the hypertension in the first 2 patients seems clear: both were normotensive before transplantation, graft function was excellent on low-dose steroid therapy and peripheral renin activity was markedly elevated in both bilaterally-nephrectomized patients. Following dilatation of the stenoses, the normalization in BP bore a close temporal relationship to the fall in plasma renin activity (Table 1).

The third patient was unusual in that he was not hypertensive; however, it seems clear from the results of pre-dilatation pressure recordings and the

TABLE 1. Reduction in blood pressure and plasma renin activity (PRA) following percutaneous transluminal dilatation (PTA) of transplant artery stenosis

\begin{tabular}{|c|c|c|c|c|}
\hline & Case & Time & $\mathrm{BP}(\mathrm{mmHg})$ & $\operatorname{PRA}(\mu \mathrm{g} / \mathrm{l} / \mathrm{hr})$ \\
\hline \multirow[t]{2}{*}{1.} & $\begin{array}{l}\text { D.H. } \\
\text { PTA: }\end{array}$ & $\begin{array}{r}24 / 10 / 79 \\
31 / 10 / 79 \\
1 / 11 / 79\end{array}$ & $\begin{array}{l}170 / 125^{*} \\
160 / 110^{*}\end{array}$ & $\begin{array}{l}56 \cdot 1 \\
-\end{array}$ \\
\hline & & $\begin{array}{l}+6 \mathrm{hr} \\
+48 \mathrm{hr} \\
+72 \mathrm{hr}\end{array}$ & $\begin{array}{l}145 / 85 \dagger \\
130 / 80 \dagger \\
130 / 90 \dagger\end{array}$ & $\begin{array}{l}48 \cdot 1 \\
18 \cdot 6 \\
-\end{array}$ \\
\hline 2. & $\begin{array}{l}\text { O.N. } \\
\text { PTA: }\end{array}$ & $\begin{array}{l}15 / 8 / 79 \\
12 / 11 / 79 \\
13 / 11 / 79\end{array}$ & $\begin{array}{l}160 / 110^{*} \\
160 / 110^{*}\end{array}$ & $\begin{array}{l}26 \cdot 8 \\
-\end{array}$ \\
\hline & & $\begin{array}{l}+6 \mathrm{hr} \\
+24 \mathrm{hr} \\
+72 \mathrm{hr}\end{array}$ & $\begin{array}{l}130 / 90 \dagger \\
140 / 100 \dagger\end{array}$ & $\begin{array}{r}5 \cdot 1 \\
2 \cdot 2 \\
-\end{array}$ \\
\hline
\end{tabular}

* Multi-agent antihypertensive therapy; $\uparrow$, no medication.

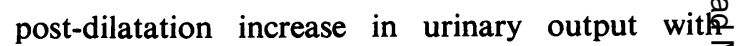
eventual functional recovery, that the stenosis was significant factor in the non-function of the grafe (Table 2).

TABLE 2. Urine output and serum creatinine in relation transplantation and percutaneous transluminal angioplast (PTA) at 3-day intervals

\begin{tabular}{|c|c|c|c|}
\hline Case & Time & $\begin{array}{l}24 \text { hr urine } \\
\text { output }(\mathrm{ml})\end{array}$ & $\begin{array}{c}\text { Serum } \\
\text { creatinine } \\
(\mu \mathrm{mol} / \mathrm{l})\end{array}$ \\
\hline \multirow[t]{7}{*}{ R.B. } & Post-transplant & & \\
\hline & day 2 & 1210 & 1326 \\
\hline & 5 & 1495 & $1361 \cdot 4$ \\
\hline & 8 & 350 & $1025 \cdot 4$ \\
\hline & 11 & 1125 & $1308 \cdot 3$ \\
\hline & 14 & 270 & 1158.4 \\
\hline & 17 & 510 & $1025 \cdot 4$ \\
\hline \multirow[t]{7}{*}{ PTA: } & 19 & & $955 \cdot 0$ \\
\hline & 20 & 1405 & $1184 \cdot 6$ \\
\hline & 23 & 1475 & $955 \cdot 0$ \\
\hline & 26 & 2200 & $998 \cdot 9$ \\
\hline & 29 & 3015 & $733 \cdot 7$ \\
\hline & 32 & 3050 & $450 \cdot 8$ \\
\hline & 35 & 1925 & $406 \cdot 6$ \\
\hline \multicolumn{4}{|c|}{ (3-day intervals no longer possible owing to absence) } \\
\hline & 43 & 3950 & 353.6 \\
\hline & 47 & 3300 & $282 \cdot 9$ \\
\hline
\end{tabular}

Haemodialysis on days 2, 5, 7, 10, 11, 14, 17 and 20.

Percutaneous transluminal angioplasty by technique of Grüntzig has gained increasing accep tance since his first published work. More recend reports have attested to its efficacy in other than peripheral obstructive disease, namely disease of both renal and coronary arteries (Grüntzig, 1978) Recent reports describe the use of the technique in transplant renal artery stenosis with hypertensiof and the technique has also been used in solitary native kidneys for control of hypertension ans preservation of renal function with good results. (Weinberger et al., 1979), this situation being. similar to the 2 patients who had solitary transplanis kidneys.

The technique is both relatively easy to use andु effective in this situation, in contrast to the difficult of re-operation on a transplant kidney, as evidence in patient O.N. It is repeatable as shown by Millan Mast and Madias (1979), and has also been showiv to be of use in the single kidney situation (Weinf berger et al., 1979). The authors feel that this should therefore be strongly considered as a viable alterna ${ }_{\sigma}^{\omega}$ tive to surgery for treatment of renovascular hypers tension, or graft dysfunction, in the renal transplant patient with renal artery stenosis.

\section{References}

Diamond, N.G., Casarella, W.J., Hardy, M.A. \& Appelष G.B. (1979) Dilatation of critical transplant renal arter $\frac{\rho}{\mathbb{Q}}$ 
stenosis by percutaneous transluminal angioplasty. American Journal of Roentgenology, 133, 1167.

GrüNTZIG, A. (1978) Transluminal dilatation of coronary artery stenosis. Lancet, i, 263.

Grüntzig, A., KuhlmanN, U., Vetter, W. \& Lutolf, U. (1978) Treatment of renovascular hypertension with percutaneous transluminal dilatation of a renal artery stenosis. Lancet, i, 801.

Katzen, B.T., Change, J., Lukowsky, G.H. \& Abramson, E.G. (1979) Percutaneous transluminal angioplasty for treatment of renovascular hypertension. Radiology, 131, 53.

Kauffman, H.M., Sampson, D., Fox, P.S. \& Doyle, T.J. (1977) Prevention of transplant renal artery stenosis. Surgery, 81, 161.

Mathias, K., RaU, W. \& Kauffman, G. (1979) Katheterdilatation einer Arterienstenose nach Nierentransplantation. Deutsche medizinische Wochenschrift, 104, 437.

Millan, V.G., Mast, W.E. \& Madias, N.E. (1979) Nonsurgical treatment of severe hypertension due to renal artery intimal fibroplasia by percutaneous transluminal angioplasty. New England Journal of Medicine, 300, 1371.
Ricotta, J.J., Schaffe, H.V., Williams, G.M. \& Rolley, R.T. (1978) Renal artery stenosis following transplantation: etiology, diagnosis and prevention. Surgery, 84, 595.

Schramek, A., BetTer, O.S., Adler, O. \& Tuma, S. (1975) Hypertensive crisis, erythrocytosis and uraemia due to renal artery stenosis of kidney transplants. Lancet, i, 70. Schwarten, D.E., Yune, H.Y., Klatte, E.C., Grim, C.E. \& WeInberger, W.H. (1980) Clinical experience with percutaneous transluminal angioplasty of stenotic renal arteries. Radiology, 135, 601.

Sniderman, K.W., Sos, T.A., Sprayregens, S., Saddekhi, S., Cheigh, J.S., TAPia, C., Tellis, Y. \& Veith, F.J. (1980) Percutaneous transluminal angioplasty in renal transplant artery stenosis for relief of hypertension. Radiology, 135, 23.

Tegtmeyer, C.J., Dyer, R., Teates, C.D., Ayers, C.R., Carey, R.M., Wellons, H.A. \& Stanton, C.W. (1980) Percutaneous transluminal dilatation of the renal arteries. Radiology, 135, 589.

Weinberger, W.H., Yune, H.Y., Grim, C.E., Luft, F.C., Klatte, E.C. \& DonohUe, J.P. (1979) Percutaneous transluminal angioplasty for renal artery stenosis in a solitary functioning kidney. Annals of Internal Medicine, 91, 684. 